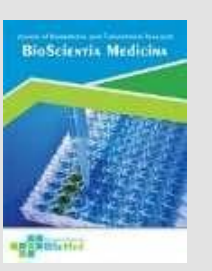

Bioscientia Medicina: Journal of Biomedicine \& Translational Research

Journal Homepage: www.bioscmed.com

\title{
The Role of Health Officer Related to Adherence to Iron Tablet Supplementation among Pregnant Women in Central Aceh in 2021
}

\section{Sri Wahyuni MS ${ }^{\star}{ }^{*}$ Barirah Madeni ${ }^{1}$, Hasritawati ${ }^{1}$}

${ }^{1}$ Diploma of Midwifery, Central Aceh Health Polytechnic, Aceh, Indonesia

\author{
A R T I C L E I N F O \\ Keywords: \\ Pregnancy \\ Iron supplementation \\ Health counselor \\ Nutrition \\ *Corresponding author: \\ Sri Wahyuni.MS

\section{E-mail address: \\ sriwahyuni15117999@gmail.com}

All authors have reviewed and approved the final version of the manuscript.

https://doi.org/10.37275/bsm.v6i4.485

\begin{abstract}
A B S T R A C T
Background. Coverage of $\mathrm{Fe}$ tablets in Aceh Tengah District is very low, even lower than other districts in Aceh; namely 12.4 percent for Fe 1 and 10.56 percent for Fe3. Failure to distribute these tablets in this district may lead to an increase in the prevalence of anemia. One of the reasons is that the monitoring, recording, and reporting system by health officers in consuming Fe tablets and in routinely checking $\mathrm{Hb}$ levels is not good enough. This study aims to analyze the effect of the role of leadership (customers, communicators, motivators, facilitators, and counselors) on the adherence of pregnant women to consuming Fe tablets in the Central Aceh Regency in 2021. Methods: This type of research is a survey with a cross-sectional approach. The population is all pregnant women in the Aceh Tengah Regency area with a gestational age of more than 20 weeks, or it could be less than 20 weeks, provided that this is the first visit and has made a health visit at the health center. Methods of collecting data by interviewing and checking the health development of pregnant women with Editing, Coding, Entry, and Cleaning. Data were analyzed by univariate, bivariate, and multivariate. Results: The results of the multivariate analysis with logistic regression obtained the facilitator variable has the greatest influence on compliance in consuming $\mathrm{Fe}$ tablets with a value of $\mathrm{OR}=14,166$ meaning pregnant women who accept the role of health officers as facilitators will obediently consume Fe tablets as much as 14,166 times when compared to mothers who do not accept the role of health officers as customers. Conclusion: The low adherence to Fe tablet consumption was due to the fact that the number of $\mathrm{Fe}$ tablets given by health officers to pregnant women in Aceh Tengah Regency was not up to the standard, which was 90 tablets. Customers and facilitators have a relationship with the adherence of pregnant women to consuming Fe tablets. The facilitator has the greatest influence on compliance in consuming Fe tablets.
\end{abstract}

\section{Introduction}

Iron supplementation needs to be applied even to women with good nutritional status, because pregnant women's need for iron increases by 200-300\%. This amount is impossible to meet only through diet. ${ }^{1}$ Supplementation of $\mathrm{Fe}$ tablets is one strategy to increase iron intake that is successful only if the individual adheres to the rules of his consumption.2
Anemia is a condition in which the body has too few red blood cells (erythrocytes), which contain hemoglobin which functions to carry oxygen to all body tissues. ${ }^{3}$ Data from the 2015 Indonesian Health Demographic Survey (IDHS) The maternal mortality rate (MMR) in Indonesia reached 359 per 100,000 live births. the biggest cause of maternal mortality (MMR) 
is bleeding and one of the causes of bleeding is anemia which is also an indirect cause of maternal death, especially in pregnancy. 4

Several factors that can cause anemia in pregnancy include gravid, age, parity, education level, economic status, and compliance with Fe tablet consumption. ${ }^{5}$ Data on the distribution coverage of Fe1 tablets in Indonesia are $69.14 \%$ and $59.62 \%$ for $\mathrm{Fe} 3$. In Aceh Province in 2020, the distribution of $\mathrm{Fe} 1$ tablet coverage was $69.38 \%$ and $57.19 \%$ for Fe3. ${ }^{7}$ The lowest coverage was in Aceh Tengah District, namely $12.40 \%$ for $\mathrm{Fe} 1$ and $10.56 \%$ for Fe3. In Aceh Tengah District, the lowest coverage was in Bebesen Sub-district at 0.56\% for $\mathrm{Fe} 1$ and Pegasing, Kebayakan, and Lut Tawar Sub-districts at $0 \%$ for Fe3. Failure to achieve the distribution target of Fe tablets in these districts can increase the prevalence of anemia.

According to the guidelines of the Indonesian Midwives Association, in the management of anemia in pregnancy, midwives must give $\mathrm{Fe}$ tablets to all pregnant women and at each antenatal visit, provide counseling about nutrition, foods that contain iron and are rich in vitamin $\mathrm{C}$ and ask whether pregnant women take Fe tablets according to the guidelines. provision. ${ }^{7}$ In everyday reality, it is often found that there are problems with the low role of officers in health services, for example, patients are rarely allowed to express their opinions or feelings, often officers provide too much information and speak in a paternalistic style and demean patients. Another problem is patient dissatisfaction in the counseling process. $40-50 \%$ of patients do not fully comply with the instructions of health officers, for example, do not take medicine according to the dosage or even use other drugs besides the medicine given by the officer. Whereas patient compliance with the doctor is satisfied with the results of the consultation and counseling process. This study aims to analyze the influence of the role of leadership (customers, communicators, motivators, facilitators, and counselors) on the adherence of pregnant women to consuming Fe tablets in the Central Aceh Regency in 2021.

\section{Methods}

This type of research is a survey with a crosssectional approach. The research was conducted in Central Aceh District. This study started from February 2021 to July 2021. The population in this study were all pregnant women who were in the Central Aceh Regency area and had made health visits to health care facilities in the working area of the health center totaling 291 people. Sampling using the hypothesis test formula for the difference in the proportion of one sample by considering an error of $5 \%$, test power of $90 \%$, and a difference in the proportion of $80 \%$ by taking into account the non-response factor of $10 \%$, obtained a large sample of 208 mothers. Random sampling using a random number table.

Data collection was carried out with primary data obtained directly from respondents through interviews guided by the questionnaire that had been prepared. The primary data in this study were data on the role of health officers as customers, communicators, motivators, facilitators, counselors, and data on the compliance of pregnant women in consuming $\mathrm{Fe}$ tablets. Secondary data is data obtained from the profiles of the Aceh Tengah and Aceh Province Health Offices for 2019-2020 and other literature in the form of reading materials that are relevant to the research objectives.

The data that has been collected will be analyzed by univariate, bivariate, and multivariate. The method of data analysis in this research is to use multiple logistic regression with the consideration that this analysis technique can provide answers regarding the magnitude of the influence of the independent variable on the dependent variable in the form of categorical data at the $95 \%$ confidence level. 


\section{Results}

Table 1.The results of the bivariate analysis between the influence of the role of health office on the compliance of pregnant women in consuming Fe tablets in Central Aceh Regency in 2021

\begin{tabular}{|c|c|c|c|c|c|c|c|c|}
\hline \multirow{3}{*}{ No. } & \multirow{3}{*}{$\begin{array}{l}\text { Variable Role of } \\
\text { Health Officer }\end{array}$} & \multicolumn{4}{|c|}{ Compliance } & \multirow{3}{*}{ Total } & \multirow{3}{*}{$\%$} & \multirow{3}{*}{ P-value } \\
\hline & & \multicolumn{2}{|c|}{ Compliance } & \multicolumn{2}{|c|}{ Non-compliant } & & & \\
\hline & & $\mathrm{N}$ & $\%$ & $\mathrm{n}$ & $\%$ & & & \\
\hline \multirow[t]{3}{*}{1.} & Customer & & & & & & & \\
\hline & a. Good & 64 & 35.4 & 117 & 64.6 & 181 & 100.0 & 0.007 \\
\hline & b. Less & 2 & 7.4 & 25 & 92.6 & 27 & 100.0 & \\
\hline \multirow[t]{3}{*}{2.} & Communicator & & & & & & & \\
\hline & a. Good & 42 & 28.8 & 104 & 71.2 & 146 & 100.0 & 0.213 \\
\hline & b. Less & 24 & 38.7 & 38 & 61.3 & 62 & 100.0 & \\
\hline \multirow[t]{3}{*}{3.} & Motivator & & & & & & & \\
\hline & a. Good & 49 & 30.8 & 110 & 69.2 & 159 & 100.0 & 0.738 \\
\hline & b. Less & 17 & 34.7 & 32 & 65.3 & 49 & 100.0 & \\
\hline \multirow[t]{3}{*}{4.} & Facilitator & & & & & & & \\
\hline & a. Good & 1 & 4.3 & 120 & 64.9 & 23 & 100.0 & 0.006 \\
\hline & b. Less & 65 & 35.1 & 22 & 95.7 & 185 & 100.0 & \\
\hline \multirow[t]{3}{*}{5.} & Counselors & & & & & & & \\
\hline & a. Good & 39 & 27.9 & 101 & 72.1 & 140 & 100.0 & 0.118 \\
\hline & b. Less & 27 & 39.7 & 41 & 60.3 & 68 & 100.0 & \\
\hline
\end{tabular}

The results of the univariate test found that the role of health officer in Central Aceh Regency was very good, but the compliance of pregnant women in consuming Fe tablets was still very low, namely only $6 \%$ of 208

Table 2. Multivariate analysis of the effect of the role of health officers on the compliance of pregnant women in consuming Fe tablets in Central Aceh Regency in 2021

\begin{tabular}{|c|l|c|c|}
\hline No. & \multicolumn{1}{|c|}{ Variable } & P-value & Exp (B) \\
\hline 1. & Customer & 0.018 & 6.596 \\
\hline 2. & Facilitator & 0.037 & 14,166 \\
\hline \multicolumn{2}{|l|}{ Constant } & 0.000 & 748.687 \\
\hline \multicolumn{2}{|l}{ Overall Percentage } & $75.5 \%$ & \\
\hline
\end{tabular}

The results of multivariate analysis with logistic regression test found that the variable that had a significant effect on adherence to consuming Fe tablets was the customer with $\mathrm{P}$-value $=0.018$ and facilitator variable with $\mathrm{P}$-value $=0.037$. When viewed from the value of $\operatorname{Exp}(\mathrm{B})$ or OR (Odds ratio), then the facilitator variable has the greatest influence on the compliance of pregnant women. After the bivariate test was carried out, it was found that only one variable affected the dependent variable, namely the counselor. pregnant women in consuming Fe tablets with an $\mathrm{OR}=$ 14,166 meaning that pregnant women who accept the role of health officers as facilitators will obediently consume $\mathrm{Fe}$ tablets as much as 14,166 times when compared to mothers who do not accept the role of facilitator well from the health officers. 


\section{Discussion}

\section{The effect of the role of health officers on the compliance of pregnant women in consuming $\mathrm{Fe}$ tablets}

The results showed that the indicator of the number of Fe tablets given by health officers in the Central Aceh District to pregnant women was not following the Indonesian Ministry of Health (2015) standard, which was 90 tablets during pregnancy. Pregnant women only receive about 7-15 tablets per visit or 20-45 tablets during pregnancy. Bivariate analysis showed that among pregnant women who stated that health officers in providing midwifery services (customers) could play a good role, as many as $35.4 \%$ were obedient to consuming Fe tablets. On the other hand, pregnant women who stated that the officers had less role to play were $7.4 \%$ obedient to consuming $\mathrm{Fe}$ tablets. The results of the chi-square test show that there is a significant effect between the role of health officers as customers and the compliance of pregnant women in consuming Fe tablets.

The results showed that among pregnant women who stated that health officers could play a good role as communicators or in providing information about $\mathrm{Fe}$ tablets, as many as $28.8 \%$ were obedient in consuming Fe tablets, and pregnant women who stated the role of officers as communicators were not good, only $38.7 \%$. obediently consume $\mathrm{Fe}$ tablets. test analysis Chisquare obtained $\mathrm{P}$-value $=0.213(\mathrm{P}>0.05)$ which means that there is no significant effect between the role of health officers as communicators and the compliance of pregnant women in consuming Fe tablets.

The measurement results among pregnant women who stated that health officers could play a good role as a motivator (providing support to pregnant women in consuming $\mathrm{Fe}$ tablets), as many as $30.8 \%$ were obedient to taking Fe tablets and pregnant women who stated that the role of officers as motivators was not good, only $34,7 \%$ adhere to Fe tablets. The results of the chi-square obtained P-value $=0.738(\mathrm{P}>0.05)$ which means that there is no significant effect between the role of health officers as motivators and the compliance of pregnant women in consuming $\mathrm{Fe}$ tablets.
Bivariate analysis between facilitator and compliance variables found that among pregnant women who stated that health officers could play a good role as facilitators, $4.3 \%$ were obedient to consuming Fe tablets, and pregnant women who stated the role of officers as facilitators were not good as many as $35.1 \%$ adhered to consuming $\mathrm{Fe}$ tablets. analysis Chi-square obtained a value of $\mathrm{P}=0.006(\mathrm{P}<0.05)$ which means that there is a significant effect between the role of health officers as facilitators and the compliance of pregnant women in consuming $\mathrm{Fe}$ tablets.

The results showed that among pregnant women who stated that health officers could play a good role as counselors, as many as $27.9 \%$ were obedient in consuming Fe tablets, and pregnant women who stated that their role as counselors was not good, only $39.7 \%$ were obedient in consuming Fe tablets. test analysis Chi-square obtained $\mathrm{P}$-value $=0.118(\mathrm{P}>0.05)$ which means that there is no significant effect between the role of health officers as counselors and the compliance of pregnant women in consuming Fe tablets. The results of the further analysis showed that 2 variables had a significant effect on compliance, namely the facilitator and customer with a P-value of $<0.05$ so that these two variables could be continued to the multivariate test.

The results of multivariate analysis with logistic regression test showed that the variables that had a significant effect on adherence to consuming Fe tablets were the customer with $\mathrm{P}$-value $=0.018$ and the facilitator variable with $\mathrm{P}$-value $=0.037$. When viewed from the value of $\operatorname{Exp}(\mathrm{B})$ or OR (Odds ratio), then the facilitator variable has the greatest influence on the compliance of pregnant women in consuming Fe tablets with an OR $=14,166$ meaning that pregnant women who accept the role of health officers as facilitators will obediently consume Fe tablets as much as 14,166 times when compared to mothers who do not accept the role of facilitator well from the health officers.

Health officers in Central Aceh Regency in principle have not played their role properly in providing midwifery care to pregnant women, because not all midwifery services are carried out according to 
standards. For example, in examining the condition of the nails and skin of pregnant women, only $16 \%$ of the officers did it, as well as the examination of the circumference of the upper arm and eyelids (conjunctiva), not all officers carried out the examination.

The recommendation for checking $\mathrm{Hb}$ levels in the laboratory has not been fully implemented by the officers. This is not following the instructions from the Ministry of Health of the Republic of Indonesia that every pregnant woman who visits the health center should have her $\mathrm{Hb}$ level checked. This examination, according to Osman et al., is carried out at least 2 times during pregnancy, namely the first and third trimesters. ${ }^{8}$

Midwives must provide midwifery care following the standardization of services in the management of anemia that has been set by IBI in 2016, namely checking anemia status on the first visit of pregnant women, taking a history of health history, and filling out the KMS for pregnant women or the $\mathrm{MCH}$ book or mother card completely. and check $\mathrm{Hb}$ levels.

Good service is a factor that determines a person's compliance to follow the advice of health officers. The results showed that the compliance of pregnant women in consuming Fe tablets in Central Aceh Regency was still very lacking, one of the reasons was because the Fe tablets given by health officers were not following the instructions of the Indonesian Ministry of Health (2015) which was 90 tablets during pregnancy, so that after further analysis by removing the indicator of the number of $\mathrm{Fe}$ tablets taken which is a confounder of the compliance variable, the results of the study changed, namely $37 \%$ of pregnant women were declared obedient to consuming Fe tablets.

The results of the further analysis with a bivariate test found that there was a significant effect between the role of health officers as customers and the compliance of pregnant women in consuming $\mathrm{Fe}$ tablets. And the results of multivariate analysis with logistic regression test found that the facilitator variable had the greatest influence on the compliance of pregnant women in consuming Fe tablets with an OR $=14,166$ meaning that pregnant women who received good services from health officers would obediently consume Fe tablets as much as 14,166 times. This is because pregnant women who have met and received good service from health officers have complied with the officer's recommendations when viewed from how to take Fe tablets, changes in stool color, changes in $\mathrm{Hb}$ levels, and the healthy development of pregnant women.

Even though from the respondents' answers, only $40 \%$ of midwives asked questions about how to take $\mathrm{Fe}$ tablets and only $42 \%$ of midwives asked about food and drinks taken with Fe tablets, but the way mothers take Fe tablets is still correct, this is due to the habit of taking Fe tablets. The community says that taking medicine must be with plain water, not sweet water such as tea, coffee, and milk, and taking medicine is usually done in the morning or at night before going to bed, while the habit of eating young mangoes is usually done during the day.

The results of the study in Central Aceh Regency showed that in carrying out their role as communicators, namely providing messages or information about Fe tablets to pregnant women, the majority of health officers had played a good role, for example, midwives were very friendly and friendly, looked quite clean, polite and attractive and used the language. easy to understand and allow an opinion. However, in providing information about anemia such as food and drinks that should not be taken together with Fe tablets and how to take the right medicine, midwives have not entirely done it. This information is very necessary because the wrong way of drinking will inhibit the absorption of iron into the body. Absorption of iron can increase when there is the acid in the stomach and can be inhibited when taken with food and drinks containing alcohol, tea, coffee, chocolate, fruits that contain alcohol (such as durian, pineapple, mango, kuini). A good way to drink is to drink vitamin $\mathrm{C} / \mathrm{juice} /$ citrus fruit or drink it with meat or fish to stimulate stomach acid. 9

As health care officers, they should be able to provide complete information to pregnant women, to increase their knowledge and understanding of anemia in pregnancy. The appearance of an attractive and 
friendly officer without being followed by the provision of clear information will affect a person's adherence to the treatment program.

The chi-square showed that there was no significant effect between the role of health officers as communicators and the compliance of pregnant women in consuming Fe tablets, meaning that whether or not pregnant women complied in consuming Fe tablets was not determined from the results of communication with officers. The existence of this wrong perception is caused because the officers have not carried out their role well as communicators.

According to IBI (2016) officers must ask whether pregnant women take $\mathrm{Fe}$ tablets following the provisions and whether the supply is sufficient. Listen to the complaints expressed by the mother with great interest and keep in mind that all mothers need moral support during their pregnancy. Health officers in Central Aceh Regency have played a good role in providing moral support to mothers to consume $\mathrm{Fe}$ tablets, the majority of respondents stated that midwives had recommended pregnant women to take at least 1 tablet of Fe per day as much as 91\% to $98 \%$. Around $84 \%$ of pregnant women also stated that the midwife advised the mother to immediately return to the health officer when the medicine had run out and gave confidence to the mother that by taking Fe tablets, the risk of bleeding during pregnancy and childbirth could be prevented.

The results of the analysis showed that there was no significant effect between the role of health officers as motivators and the compliance of pregnant women in consuming Fe tablets. This means that there is no difference in compliance between pregnant women who receive support from officers and those who do not. This is because although the officers have advised the mother to come back when the medicine runs out, not all mothers are willing to visit again because they are busy working and taking care of the family. Likewise, with the recommendation to take 1 tablet per day, pregnant women also do not do it because they are worried that taking the drug will increase blood pressure and harm the fetus.

The results of the study indicate that the role of health officers as facilitators of Fe tablets in the Central Aceh District is still lacking. In the health center or health service places, Fe tablets are indeed available, but only about 27 to $28 \%$ of pregnant women stated that they received 30 tablets per visit and not all of them were given free of charge to pregnant women, they generally only received 7-15 tablets per visit.

The results of the interview on March 5, 2021, the Central Aceh District health officer explained that the reason for giving Fe tablets that were not following the treatment program was because pregnant women did not want to take the tablets and to get the rest it was hoped that pregnant women would be willing to return to health officers or the posyandu.

This condition is certainly not following government recommendations as stated in the Indonesian Ministry of Health (2015) that pregnant women until the postpartum period are required to take 1 tablet of Fe a day (60 mg elemental iron) and $0.25 \mathrm{mg}$ of folic acid in a row for a minimum of 90 days of pregnancy until 42 days after delivery and start giving at the time the pregnant woman first checks her pregnancy or K1.

The results of the further analysis found that there was a significant effect between the role of health officers as facilitators and the compliance of pregnant women in consuming Fe tablets. Multivariate analysis with logistic regression test found that the customer variable had a significant influence on the compliance of pregnant women in consuming Fe tablets with an OR $=6.596$ meaning that pregnant women who received well the role of health officers as providers of Fe tablets would obediently consume Fe tablets as much as 6.596 times.

Based on the recapitulation of respondents' answers, it can be seen that almost all pregnant women stated that the role of health officers as counselors was very good, for example in fostering good relations with pregnant women, listening to mothers' complaints while taking $\mathrm{Fe}$ tablets and stating that they were willing to help mothers in overcoming complaints experienced while taking Fe tablets.

Satisfaction with the results of counseling with health officers will certainly affect compliance in consuming Fe tablets. This is following the opinion of 
Muninjaya (2011) that the attitude of empathy (caring attitude) shown by health officers will touch the patient's emotions. This factor will affect the level of patient compliance (compliance). The results of the bivariate analysis showed that there was no effect of the role of the officer as a counselor with the compliance of pregnant women in consuming Fe tablets.

\section{Conclusion}

The low adherence to Fe tablet consumption was due to the fact that the number of Fe tablets given by health officers to pregnant women in Central Aceh Regency was not up to the standard, which was 90 tablets. Customers and facilitators have a relationship with the adherence of pregnant women to consuming Fe tablets. A facilitator has the greatest influence on compliance in consuming Fe tablets.

\section{References}

1. Suryanegara W, Wija IBEU. The relationship of knowledge, attitudes and practices of $\mathrm{Fe}$ tablet consumption of mothers with toddlers with stunting incidences in Cilembu village, Sumedang regency in 2019. J Drug Deliver Ther. 2021; 11(4).

2. Ardianti F, Dewi YLR, Murti B. Contextual effect of Posyandu on adherence to iron tablet consumption among pregnant women in Blitar, East Java. J Maternal Child Health. 2019; 4(2).

3. Wiradnyani LA, Khusun $\mathrm{H}$, Achadi EL, Ocviyanti D, Shankar AH. Role of family support and women's knowledge on pregnancy-related risks in adherence to maternal iron-folic acid supplementation in Indonesia. Pub Health Nutr. 2016; 19(15).

4. Public health Office. Data and Information Center of the Indonesian Ministry of Health Year 2012 Related to Maternal Health. 2019. www.depkes.go.id /download.php?file=downlo ad/pusdatin/info datin/ at 16:00 WIB
5. Stephen G, Mgongo M, Hashim TH, Katanga $\mathrm{J}$, Stray-Pedersen B, et al. Anemia in pregnancy: prevalence, risk factors and adverse perinatal outcomes in Northern Tanzania. Anemia. 2018; 1846280.

6. Department of Nutrition and Public Health FKM UI. Nutrition and Public Health. Jakarta: Rajawali Press. 2012.

7. Ministry of Health RI. Guidelines for the Administration of Blood Adding Tablets. Jakarta: Ministry of Health RI. 2015.

8. Osman MO, Nour TY, Bashir HM, Robie AK, Nur AM, et al. Risk factors for anemia among pregnant women attending the antenatal care unit in selected Jigjiga Public Health Facilities, Somali Region, East Ethiopia 2019; Unmatched case control studies. J Multidiscipline Health Care. 2020; 13: 76977.

9. Azhar BS, Islam MS, Karim MR. Prevalence of anemia and associated risk factors among pregnant women attending antenatal care in Bangladesh: a cross-sectional study. Primary Health Care Res Dev. 2021; 22. 